\title{
A Label-free Fluorescence Assay for Trypsin Based on the Electron Transfer between Oligonucleotide-stabilized Ag Nanoclusters and Cytochrome c
}

\author{
Mei-Lan Hong, Li-Juan LI, Hui-Xia Han, and Xia CHU \\ State Key Laboratory of Chemo/Bio-sensing and Chemometrics, College of Chemistry and Chemical \\ Engineering, Hunan University, Changsha 410082, P. R. China
}

\begin{abstract}
A label-free fluorescent assay for the detection of trypsin by using oligonucleotide-templated silver nanoclusters (Ag $\mathrm{NCs}$ ) and cytochrome $\mathrm{c}(\mathrm{Cyt} \mathrm{c}$ ) has been demonstrated. When negatively charged Ag NCs and positively charged Cyt $\mathrm{c}$ are mixed, they tend to form a hybrid complex, and then lead the fluorescence of Ag NCs to be quenched significantly due to electron transfer between Ag NCs and the heme cofactor of Cyt c. In the presence of trypsin, it catalyzes the hydrolytic cleavage of Cyt $\mathrm{c}$ to small peptide fragments, and releases the heme moiety from the Ag NCs/Cyt c complex; the quenched fluorescence restores therewith. By virtue of this specific response, the fluorescent biosensor has a linear range of from 0.7 to $4 \mu \mathrm{g} \mathrm{mL} \mathrm{m}^{-1}$ and from 9 to $120 \mu \mathrm{g} \mathrm{mL}^{-1}$ with a detection limit of $58.7 \mathrm{ng} \mathrm{mL}^{-1}$. Aside from the easy manufacture aspect, our method also possesses a high signal-to-background ratio $(\sim 11)$, excellent selectivity and good biocompatibility, which makes it a promising bioanalysis for a trypsin activity assay.
\end{abstract}

Keywords Ag nanoclusters, trypsin, cytochrome c

(Received May 3, 2014; Accepted June 16, 2014; Published August 10, 2014)

\section{Introduction}

Trypsin, a member of the protease family, is produced by pancreatic acinar cells. It is known as the most important digestive enzyme, and plays a vital role in controlling the function of pancreatic exocrine. ${ }^{1}$ A disorder in trypsin expression in the human body can cause a number of diseases, such as pancreatitis and meconium ileus. ${ }^{2-4}$ It has been clinically shown that an acute pancreatitis patient displays a much higher trypsin level than healthy people..$^{5,6}$ With this in mind, we can treat the trypsin level as a reliable and specific diagnostic biomarket for pancreatic insufficiency. ${ }^{7}$ To date, several strategies have been established for the determination of trypsin activity. Traditional methods for a trypsin activity study involve gel electrophoresis, gelatin-based film techniques, and high-performance liquid chromatography (HPLC). ${ }^{8-10}$ However, these methods require either laborious experiment procedures or sophisticated instrumentations. To solve these problems, many new methods have been reported, including colorimetry, chemiluminescence, fluorescence, and electrochemical. ${ }^{11-14,25}$ Among them, a fluorescence method has attracted immense interest owing to its rapid response and easy operation.

Recently, noble metal nanoclusters (NCs) as novel fluorescent markers have been widely applied. Compared with dye molecules or semiconductor quantum dots, they have the advantages of low toxicity and good biocompatibility. ${ }^{15}$ Notably, silver nanoclusters (Ag NCs), which have been confirmed to be

$\dagger$ To whom correspondence should be addressed.

E-mail: xiachu@hnu.edu.cn excellent fluorophores, are prosperous. Since oligonucleotide has a high affinity for metal cations, numerous studies have applied oligonucleotide as a scaffold for Ag NCs formation. ${ }^{16,17}$ These oligonucleotide-stabilized Ag NCs exhibit good photostability and outstanding biocompatibility.

Cytochrome c (Cyt c) is a metalloprotein, which plays a significant role in the mitochondrial respiratory chain. ${ }^{18}$ The metal-containing heme cofactor makes Cyt $\mathrm{c}$ an outstanding electron-transfer protein. Cyt $\mathrm{c}$ is positively charged at neutral $\mathrm{pH}$, since its isoelectric point $(\mathrm{PI})$ is around $10.0-10.5 .^{19}$ Armed with these attractive features, Cyt $\mathrm{c}$ has been used in the field of biosensors and biomaterials. . $^{13,20,25,28}$

Herein we attempt to develop a simple, specific and costeffective fluorescent method for trypsin activity assay through the combination of Cyt $\mathrm{c}$ and Ag NCs. The assay principle is elaborated in Scheme 1. We firstly synthesize oligonucleotide-

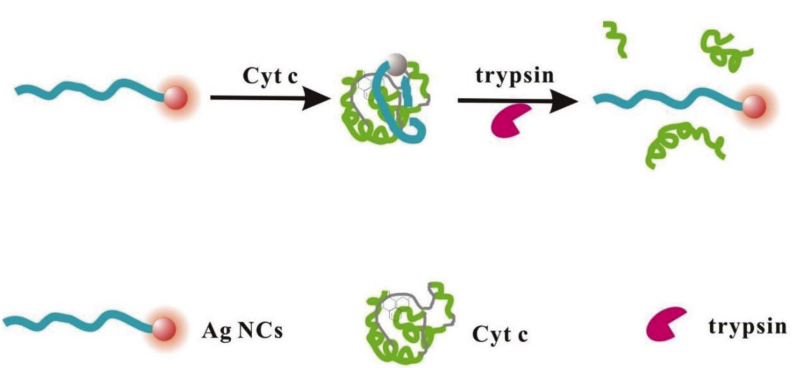

Scheme 1 Schematic illustration of the fluorescence assay for trypsin detection. 
stabilized Ag NCs by a one-pot method. The as-prepared Ag NCs are highly negatively charged due to abundant phosphate groups, while Cyt $\mathrm{c}$ is highly positively charged under our experimental conditions. When the two substances are mixed, they quickly form a hybrid complex through an electrostatic interaction, and the fluorescence of $\mathrm{Ag} \mathrm{NCs}$ is significantly quenched by the metal-containing heme in Cyt c. When trypsin is introduced to the complex solution, Cyt c could be hydrolyzed to small peptide fragments, ${ }^{21}$ which dissociates the heme cofactor from the $\mathrm{Ag} \mathrm{NCs/Cyt} \mathrm{c} \mathrm{complex} \mathrm{and} \mathrm{restores} \mathrm{the}$ fluorescence of Ag NCs. To the best of our knowledge this is the first time to employ Ag NCs and Cyt $\mathrm{c}$ as a biosensor for a trypsin activity assay; our method is simple, cost-effective and has a high signal-to-background ration.

\section{Experimental}

\section{Reagents and apparatus}

DNA oligonucleotide (5'-GGCCCTTAACCCGGGGTTAGGGTTAGGG-3'), Cyt cx, pepsin (Pep), papain (Pap), trypsin, and trypsin inhibitor (from soybean) were purchased from Sangon Biotech Co., Ltd. (Shanghai, China). Acetylcholinesterase from electrophorus electricus (electric eel) (AchE), human serum albumin (HSA), and hemoglobin ( $\mathrm{Hb})$ were purchased from Sigma-Aldrich (USA). Phospholipase D from streptomyces chromofuscus (PLD) was obtained from Merck (Darmstadt, Germany). Trishydroxymethyl aminomethane (tris) was from Roche (Basel, Switzerland). Nitric acid $\left(\mathrm{HNO}_{3}\right)$, silver nitrate $\left(\mathrm{AgNO}_{3}\right)$, and sodium borohydride $\left(\mathrm{NaBH}_{4}\right)$ were purchased from Nanjing Chemical Reagents Factory (Nanjing, China). All solutions were prepared using ultrapure water, which was obtained through a Millipore Milli-Q water-purification system (Billerica, MA), and had an electric resistance of more than $18.2 \mathrm{M} \Omega$.

Fluorescence measurements were carried out on an F-7000 fluorescence spectrometer (Hitachi, Japan). The fluorescence emission spectra of Ag NCs were recorded from 575 to $700 \mathrm{~nm}$ at room temperature with a 560-nm excitation wavelength. Transmission electron microscopy (TEM) images were obtained on a JEOL JEM 2100 TEM under an accelerating voltage of $200 \mathrm{kV}$. A dilute colloid solution of Ag NCs was pipetted onto carbon-coated copper grids, and the grids were dried naturally in air before imaging.

\section{Synthesis of oligonucleotide-stabilized Ag NCs}

Oligonucleotide-stabilized Ag NCs were synthesized according to the literature ${ }^{22}$ with slight modifications. Briefly, $15 \mu \mathrm{L}$ of DNA oligonucleotide $(100 \mu \mathrm{M})$ was mixed with $2 \mu \mathrm{L}$ of a $\mathrm{AgNO}_{3}$ aqueous solution $\left(4.5 \mathrm{mM}\right.$ ) and $\mathrm{ddH}_{2} \mathrm{O}$ (distilled and deionized $\mathrm{H}_{2} \mathrm{O}, 81 \mu \mathrm{L}$ ), followed by vigorous shaking for $30 \mathrm{~s}$. After $20 \mathrm{~min}$ of incubation in an ice-water bath, $2 \mu \mathrm{L}$ of a freshly prepared $\mathrm{NaBH}_{4}$ aqueous solution $(4.5 \mathrm{mM})$ was added, followed by vigorous shaking for $2 \mathrm{~min}$. The solution was kept in the dark at $4^{\circ} \mathrm{C}$, and allowed to undergo a $6.0 \mathrm{~h}$ reaction to form nanoclusters.

\section{The detection of trypsin}

First, $10 \mu \mathrm{L}$ of Cyt $\mathrm{c}(150 \mu \mathrm{M})$ was a mixture with different concentrations of trypsin in a Tris- $\mathrm{HNO}_{3}$ buffer $(100 \mathrm{mM}$,

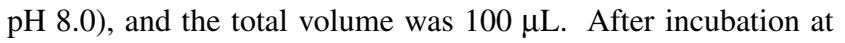
$37^{\circ} \mathrm{C}$ for $2.5 \mathrm{~h}, 10 \mu \mathrm{L}$ of the above-mentioned reaction solution was added into a mixture containing $5 \mu \mathrm{L}$ of as-prepared $\mathrm{Ag}$ $\mathrm{NCs}$ and $85 \mu \mathrm{L}$ of $\mathrm{ddH}_{2} \mathrm{O}$. The solution fluorescence spectra were measured $5 \mathrm{~min}$ later upon being excited at $560 \mathrm{~nm}$.

\section{Trypsin inhibition experiment}

The inhibition effect of a trypsin inhibitor was studied. Different concentrations of the trypsin inhibitor and $60 \mu \mathrm{L}$ of trypsin $\left(2 \mathrm{mg} \mathrm{mL}^{-1}\right)$ were pre-warmed at $25^{\circ} \mathrm{C}$ for $30 \mathrm{~min}$ to inactivate trypsin, and then $10 \mu \mathrm{L}$ of Cyt c $(150 \mu \mathrm{M})$ in $100 \mathrm{mM}$ Tris- $\mathrm{HNO}_{3}$ buffer ( $\mathrm{pH}$ 8.0) was added. This reaction was conducted in a $100 \mu \mathrm{L}$ volume. After incubation at $37^{\circ} \mathrm{C}$ for $2.5 \mathrm{~h}, 10 \mu \mathrm{L}$ of the mixture was added into a solution of as-prepared $\mathrm{Ag} \mathrm{NCs}(5 \mu \mathrm{L})$ and $\mathrm{ddH}_{2} \mathrm{O}(85 \mu \mathrm{L})$. After 5 min the fluorescence spectra were recorded upon being excited at $560 \mathrm{~nm}$. The inhibition efficiency (IE), defined as follows, was then determined for each inhibitor concentration:

$$
\mathrm{IE}=\left[F_{(\text {no inhibitor) }}-F_{\text {(inhibitor) }}\right] /\left[F_{(\text {no inhibitor })}-F_{0}\right] .
$$

Here, $F_{0}$ is the fluorescence intensity of the reaction system in the absence of both trypsin and the inhibitor; $F_{\text {(no inhibitor) }}$ and $F_{\text {(inhibitor) }}$ are the fluorescence intensity of the reaction system without or with an inhibitor in the presence of trypsin. ${ }^{23}$

\section{Results and Discussion}

\section{Characterization of Ag NCs}

Fluorescent Ag NCs were successfully prepared with the protection of the oligonucleotide. The 28-base DNA oligonucleotide, 5'-GGCCCTTAACCCGGGGTTAGGGTTAGGG-3', was used, because it contains part of a guanine-rich sequence that can enhance the fluorescence of Ag NCs. The as-prepared Ag NCs suspension was light yellow and transparent, which demonstrated that it possessed a good dispersion in water. A TEM image (Fig. 1a) shows that its diameter was about $2 \mathrm{~nm}$. As can be seen in Fig. 1b, the maximum excitation and emission wavelengths were 560 and $600 \mathrm{~nm}$, respectively. The fluorescent emission spectra response of $\mathrm{Ag} \mathrm{NCs/Cyt} \mathrm{c} \mathrm{to} \mathrm{trypsin} \mathrm{and} \mathrm{its}$ inhibitor are shown in Fig. 2. Cyt c can quench the fluorescence of $\mathrm{Ag} \mathrm{NCs}$ almost completely, after adding trypsin; corresponding, the emission intensity increased. Further added trypsin inhibitor led to a reduced degree of the fluorescence recovery. It proved that this method can be potentially applied as a biosensor for trypsin activity research.

\section{Optimization of experimental conditions}

Several parameters including the incubation time and the concentration of Cyt c were investigated. As reported before, the optimal operating $\mathrm{pH}$ of trypsin was around 8.0. ${ }^{24}$ Moreover, this $\mathrm{pH}$ value had a slight influence on the fluorescence of $\mathrm{Ag}$ NCs (Fig. S1, Supporting Information). Thus, in our assay the $\mathrm{pH}$ was set at 8.0.

The concentration of Cyt $\mathrm{c}$ is another important factor that will affect the experiment performance. In the absence of Cyt $\mathrm{c}$, $0.75 \mu \mathrm{M}$ of $\mathrm{Ag}$ NCs showed strong fluorescence. However, the fluorescence of Ag NCs gradually became reduced after adding increasing numbers of Cyt c (Fig. S2a, Supporting Information). Such a fact is mainly contributed to electron transfer between $\mathrm{Ag} \mathrm{NCs}$ and the heme cofactor of Cyt c. When the Cyt c concentration increased to $1.5 \mu \mathrm{M}$, the quenching efficiency reached to $92.8 \%$. Higher concentrations of Cyt c caused no obvious change of the fluorescence intensity (Fig. S2b, Supporting Information). Therefore, the detection for trypsin was performed with $1.5 \mu \mathrm{M}$ Cyt $\mathrm{c}$ in following experiments.

Under this condition, the relationship between the fluorescent intensity and the trypsin hydrolysis reaction time was explored. After mixing Cyt $\mathrm{c}$ with trypsin and performing incubation at $37^{\circ} \mathrm{C}$ for different time durations, $\mathrm{Ag} \mathrm{NCs}$ were added. The 

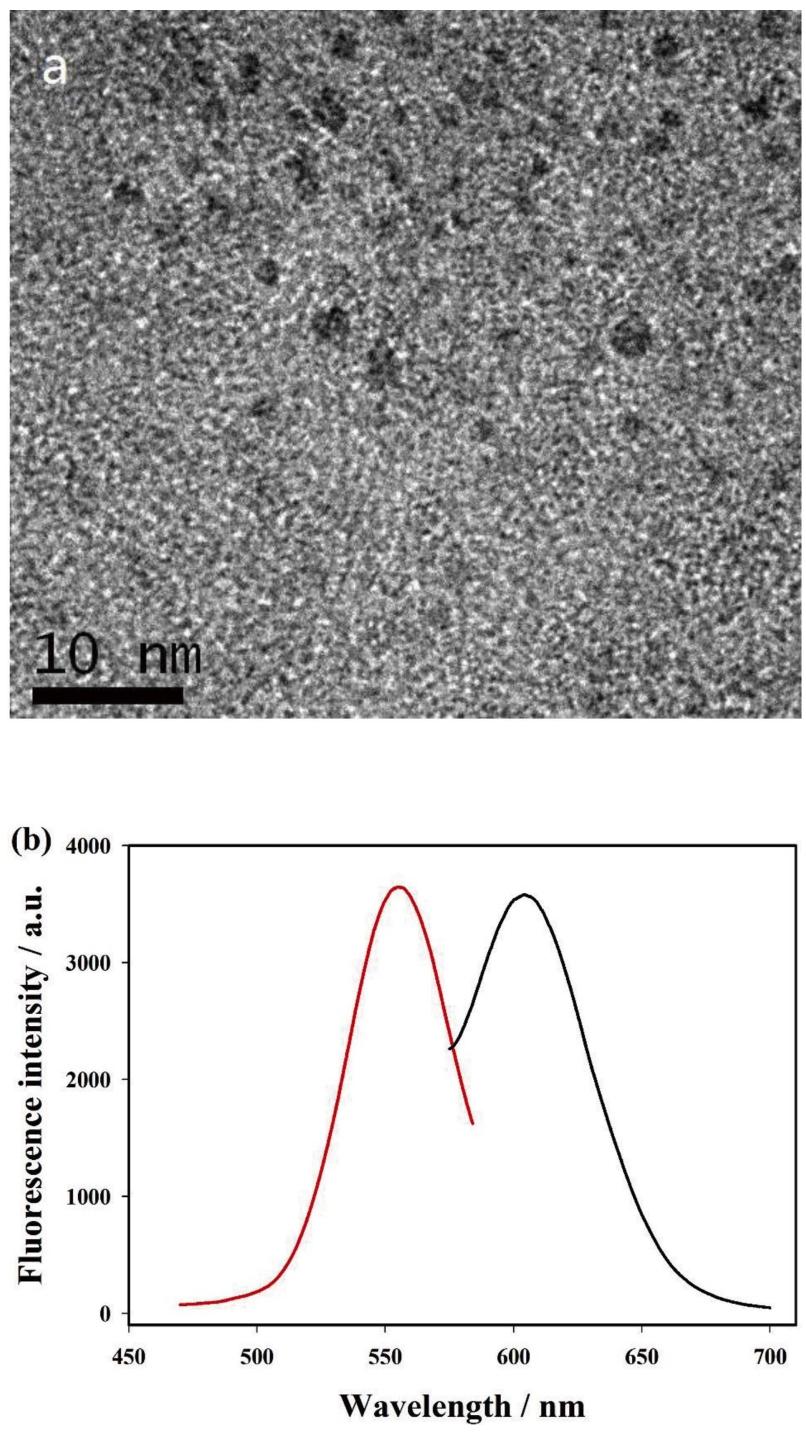

Fig. 1 (a) TEM image of Ag NCs. (b) Excitation and Emission spectra of Ag NCs. [Ag NCs] $=0.75 \mu \mathrm{M}, \lambda_{\mathrm{ex}}=560 \mathrm{~nm}$.

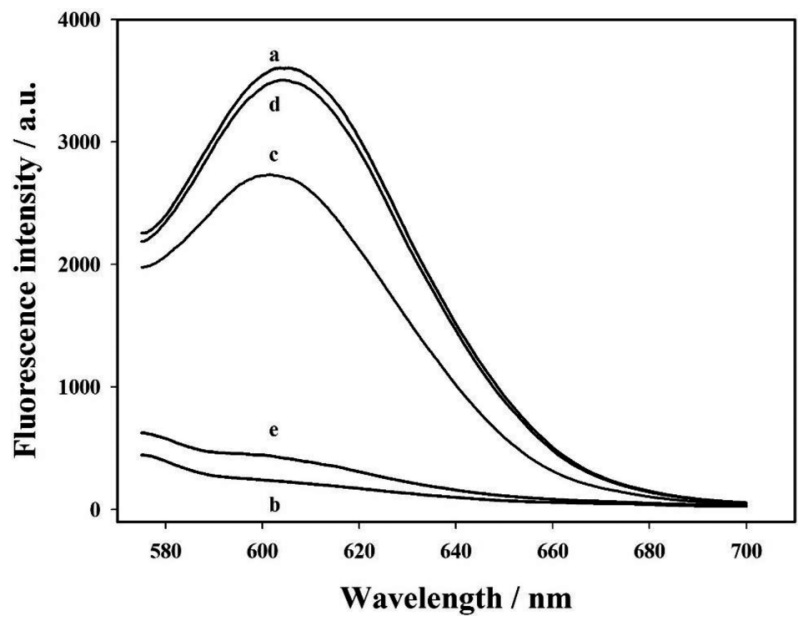

Fig. 2 Fluorescence emission spectra of (a) Ag NCs; (b) Ag NCs + Cyt c; (c) Ag NCs + Cyt c + trypsin; (d) Ag NCs + inhibitor; (e) Ag $\mathrm{NCs}+\mathrm{Cyt} \mathrm{c}+$ trypsin + inhibitor. Experimental conditions: [Ag NCs] $=0.75 \mu \mathrm{M},\left[\right.$ Cyt c] $=1.5 \mu \mathrm{M}$, [trypsin] $=120 \mu \mathrm{g} \mathrm{mL}^{-1}$ and [inhibitor] $=4.25 \mu \mathrm{g} \mathrm{mL}^{-1}$ in $10 \mathrm{mM}$ Tris- $\mathrm{HNO}_{3}$ buffer $(\mathrm{pH} 8.0), \lambda_{\mathrm{ex}}=560 \mathrm{~nm}$.
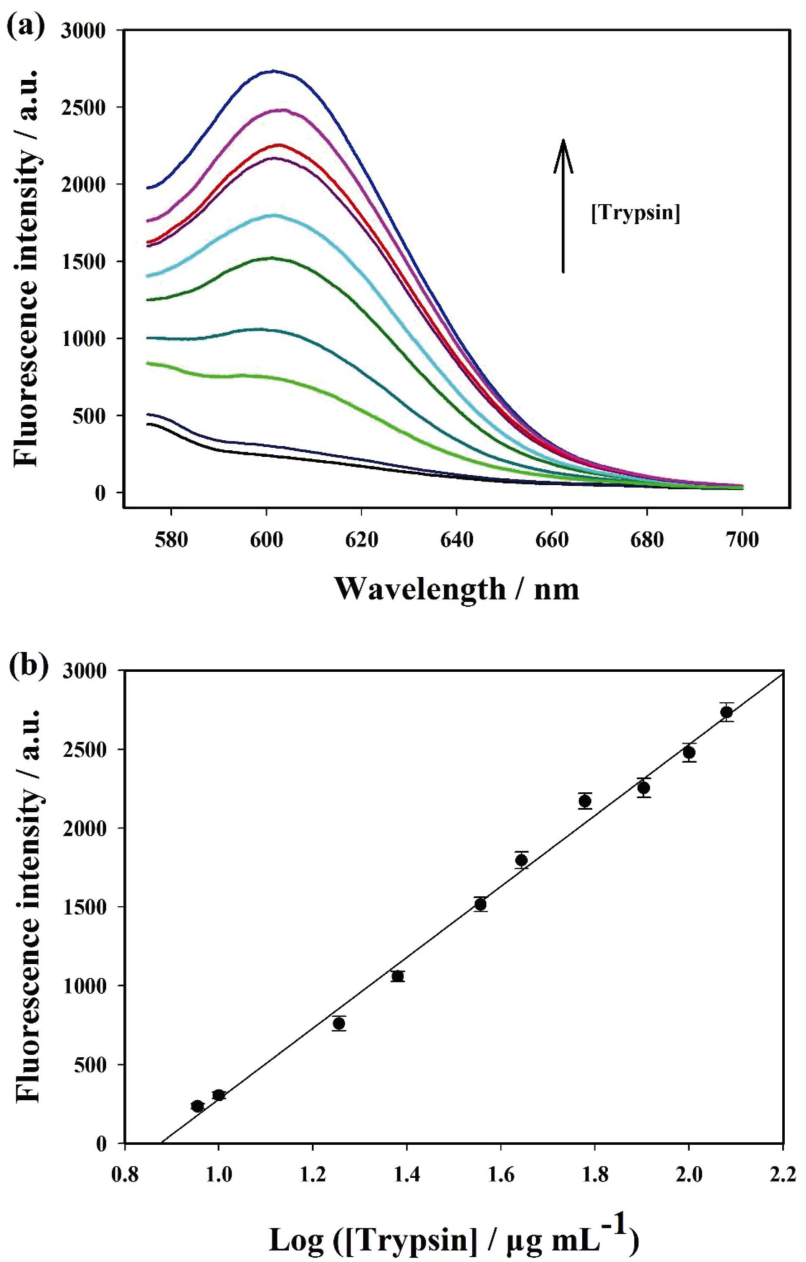

Fig. 3 (a) Fluorescence emission spectra of the $\mathrm{Ag} \mathrm{NCs} / \mathrm{Cyt} \mathrm{c}$ complex in the presence of increasing trypsin concentrations $(9,10$, $18,24,36,44,60,80,100,120 \mu \mathrm{g} \mathrm{mL}^{-1}$ ). (b) Relationship between the fluorescence intensity and the logarithmic of trypsin concentration with the error bar indicated.

corresponding emission intensity increased with time, and reached a stable value when the incubation time was prolonged to $2.5 \mathrm{~h}$ (Fig. S3, Supporting Information). Thus, in the subsequent research, $2.5 \mathrm{~h}$ was decided to be the optimization incubation period.

\section{Fluorescence assay for trypsin}

Under the optimal conditions, the application of Ag NCs and Cyt $\mathrm{c}$ for the trypsin activity assay was determined. As shown in Fig. 3a, the fluorescence of the Ag NCs/Cyt c system was restored by the addition of trypsin. In the presence of $120 \mu \mathrm{g} \mathrm{mL}^{-1}$ trypsin, a fluorescence recovery efficiency of $74.8 \%$ was obtained. It should be noted that a lack of a $100 \%$ fluorescence recovery efficiency may derive from the presence of cysteine. As reported before, in intact Cyt c, two cysteine residues were bound to the heme cofactor through a $\mathrm{C}-\mathrm{S}$ bond. ${ }^{25}$ In this situation, the bound cysteine residues had little influence on Ag NCs. However, when trypsin was introduced, it digested Cyt c to small peptides, ${ }^{26}$ and released free cysteine residues, which could decrease the fluorescence intensity of $\mathrm{Ag} \mathrm{NCs} .^{27}$ This explains why the fluorescence intensity could not restore to its initial value. As shown in Fig. 3b, a good linear relationship was obtained between the fluorescent intensity and the 

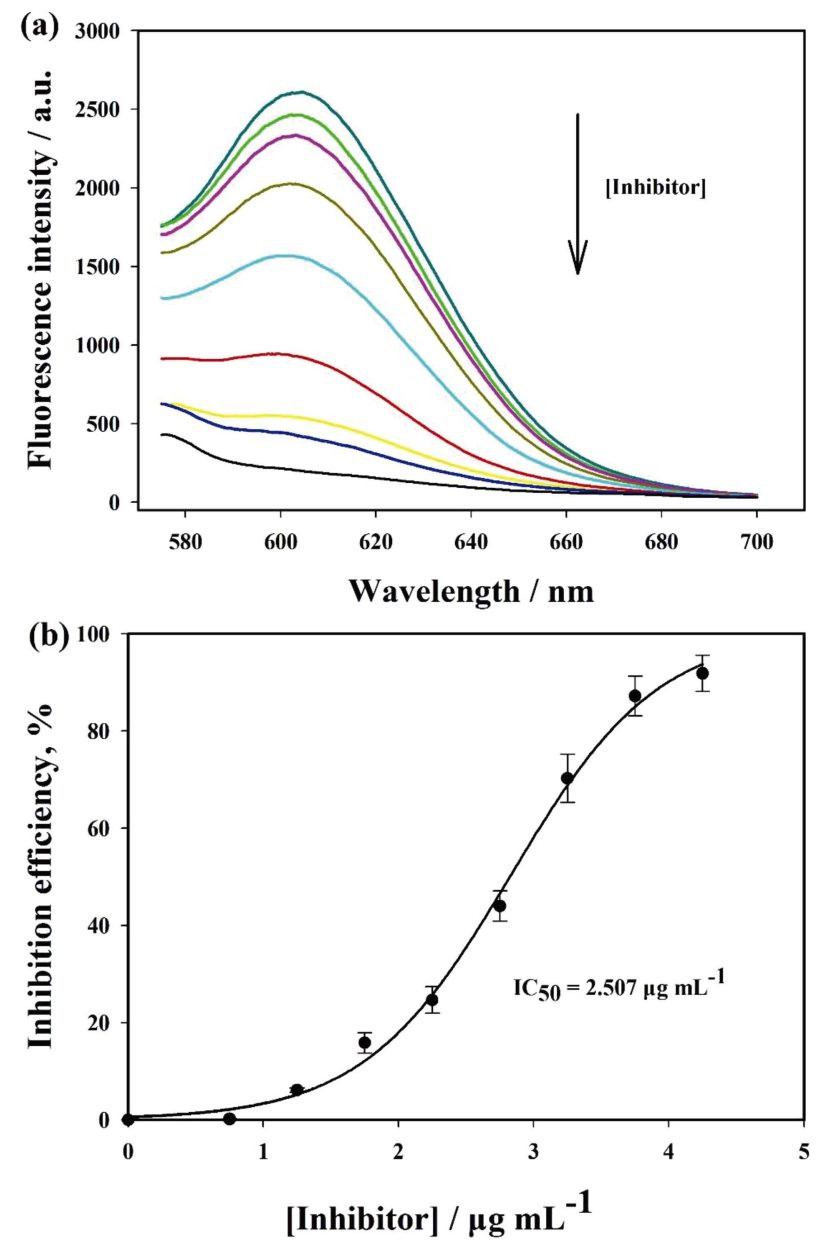

Fig. 4 (a) Fluorescence emission spectra of the Ag NCs/Cyt c complex after trypsin $\left(120 \mu \mathrm{g} \mathrm{mL}^{-1}\right)$ digesting, which was pre-incubated with increasing amounts of inhibitor $\left(0-4.25 \mu \mathrm{g} \mathrm{mL}^{-1}\right)$. (b) Plot of the inhibition efficiency vs. the inhibitor concentration $\left(0,0.75,1.25,1.75,2.25,2.75,3.25,3.75,4.25 \mu \mathrm{g} \mathrm{mL}^{-1}\right)$.

logarithmic of trypsin concentrations in the range of $9-120 \mu \mathrm{g} \mathrm{mL}^{-1}\left(R^{2}=0.993\right)$. A very interesting thing was that we observed that the fluorescence intensity get decreased with increasing amounts of trypsin in a low-concentration region, although we have not get determined the reason. A calibration curve was also obtained between the fluorescent intensity and the logarithm of the trypsin concentrations at a low region ranging from 0.7 to $4 \mu \mathrm{g} \mathrm{mL} \mathrm{L}^{-1}\left(R^{2}=0.992\right)$ (Fig. S4, Supporting Information). The detection limit for this method was estimated to be $58.7 \mathrm{ng} \mathrm{mL}^{-1}$ according to the rule of the three-times standard deviation over the blank sample, which was comparable to the reported approaches. ${ }^{28,29}$

\section{Trypsin inhibition assay}

The described method can be used to screen trypsin inhibitors because the digestion of Cyt $\mathrm{c}$ catalyzed by trypsin becomes retarded when corresponding trypsin inhibitors are present. The fluorescence spectra of $\mathrm{Ag} \mathrm{NCs}(0.75 \mu \mathrm{M})$ containing $120 \mu \mathrm{g} \mathrm{mL}^{-1}$ trypsin after incubating with different concentrations of trypsin inhibitor for $2.5 \mathrm{~h}$ at $37^{\circ} \mathrm{C}$ were recorded (Fig. 4a). The fluorescence intensity decreased with the concentration of the inhibitor increasing, indicating that the inhibitor was effective to inactivate trypsin. Based on a plot of the inhibition efficiency, which was calculated by formula (1)

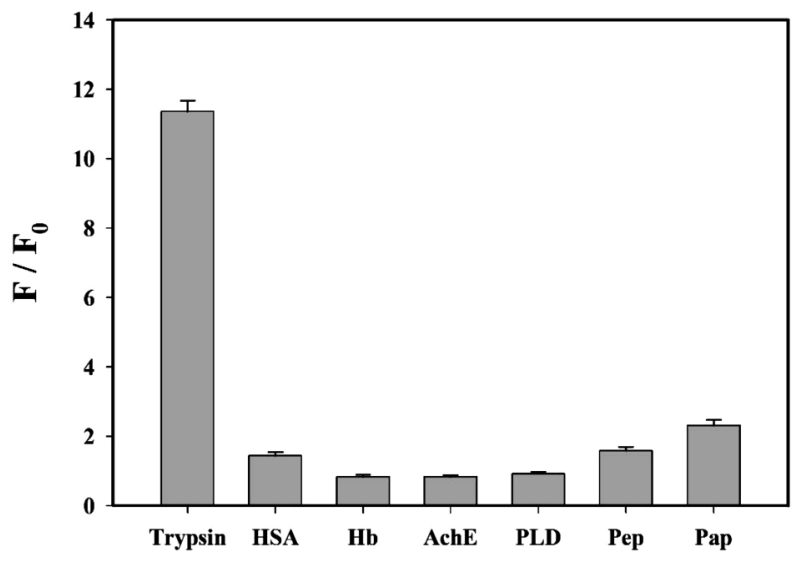

Fig. 5 Selectivity of trypsin analysis using a Ag NCs/Cyt c complex with $120 \mu \mathrm{g} \mathrm{mL}^{-1}$ trypsin, $1000 \mu \mathrm{g} \mathrm{mL}^{-1} \mathrm{HSA}, 1000 \mu \mathrm{g} \mathrm{mL}^{-1} \mathrm{Hb}$, $10.36 \mathrm{U} \mathrm{mL}^{-1}$ AchE, $40 \mathrm{U} \mathrm{mL}^{-1} \mathrm{PLD}, 200 \mu \mathrm{g} \mathrm{mL}^{-1}$ Pep or $200 \mu \mathrm{g} \mathrm{mL}^{-1}$ Pap. $F$ and $F_{0}$ are the fluorescence intensity of $\mathrm{Ag} \mathrm{NCs} / \mathrm{Cyt} \mathrm{c}$ in the presence and absence of trypsin or other proteins.

in experimental section $v s$. the concentration of inhibitor (Fig. 4b), the corresponding $\mathrm{IC}_{50}$ value was estimated to be $2.507 \mu \mathrm{g} \mathrm{mL}^{-1}$. This value is different from that determined by some reported methods, ${ }^{30,31}$ but is understandable since the $\mathrm{IC}_{50}$ value is usually vulnerable to the influence of some parameters, such as trypsin and substrate concentrations. All of these results clearly indicate that this proposed method could be used for both a trypsin activity assay and corresponding inhibitor screening.

\section{Selectivity}

Control experiments were also investigated to test the selectivity of the $\mathrm{Ag} \mathrm{NCs/Cyt} \mathrm{c} \mathrm{system} \mathrm{toward} \mathrm{trypsin.} \mathrm{A}$ number of common proteins including AchE, HSA, Hb, PLD, Pep and Pap were adopted in the assay system. Although these proteins had much higher concentrations than trypsin, only trypsin can cause obvious fluorescence recovery of the $\mathrm{Ag}$ $\mathrm{NCs} / \mathrm{Cyt} \mathrm{c}$ assay system due to the specifically hydrolyzed form of Cyt c by trypsin (Fig. 5). This result indicates that our method has superior specificity and selectivity for a trypsin activity assay.

\section{Conclusions}

In conclusion, we have successfully developed a simple and label-free fluorescence method for trypsin detection by using Cyt $\mathrm{c}$ integrated Ag NCs. This method mainly relies on the fact that positively charged $\mathrm{Cyt} \mathrm{c}$ is able to bind to negatively charged Ag NCs, and quenches its fluorescence subsequently. The prequenched fluorescence could be restored after trypsin hydrolyzing. Such an Ag NCs/Cyt c complex shows relatively high selectivity for trypsin over other proteins with a detection limit of $58.7 \mathrm{ng} \mathrm{mL}^{-1}$. Additionally, due to the low toxicity, simple synthesis, free pretreatment and size-tunable features of $\mathrm{Ag} \mathrm{NCs}$, as well as the natural substrate and commercially available characteristics of Cyt c, it holds great potential for trypsin activity related biochemical applications. 


\section{Acknowledgements}

This work was supported by the National Natural Science Foundation of China (No. 21275045), NCET-11-0121, and Hunan Provincial Natural Science Foundation of China (Grant 12JJ1004).

\section{Supporting Information}

This material is available free of charge on the Web at http:// www.jsac.or.jp/analsci/.

\section{References}

1. M. Hirota, M. Qhmuraya, and H. Baba, J. Gastroenterol., 2006, 41,832 .

2. P. G. Noone, Z. Q. Zhou, L. M. Silverman, P. S. Jowell, M. R. Knowles, and J. A. Cohn, Gastroenterology, 2001, 121, 1310.

3. D. C. Whitcomb, Gut, 1999, 45, 317.

4. F. F. Zheng, J. F. Wu, and G. C. Zhao, Anal. Methods, 2012, 4, 3932.

5. J. M. Artigas, M. E. Garcia, M. R. Faure, and A. M. Gimeno, Postgrad. Med. J., 1981, 57, 219.

6. M. F. Byrne, R. M. Mitchell, H. Stiffler, P. S. Jowell, M. S. Branch, T. N. Pappas, D. Tyler, and J. Baillie, Can. J. Gastroenterol., 2002, 16, 849.

7. P. Miao, T. Liu, X. X. Li, L. M. Ning, J. Yin, and K. Han, Biosens. Bioelectron., 2013, 49, 20.

8. W. C. Hou, H. J. Chen, T. E. Chen, and Y. H. Lin, Electrophoresis, 1983, 63, 376.

9. A. D. Kersey, T. A. Berkoff, and W. W. Morey, Opt. Lett., 1993, 18, 1370.

10. M. M. Vestling, C. M. Murphy, and C. Fenselau, Anal. Chem., 1990, 62, 2391.

11. W. X. Xue, G. X. Zhang, and D. Q. Zhang, Analyst, 2011, $136,3136$.

12. J. J. Zhang, Z. Zhang, X. Nie, Z. J. Zhang, X. C. Wu, C. Y.
Chen, and X. H. Fang, J. Nanosci. Nanotechnol., 2014, 14, 4029.

13. W. Z. Zhang, P. Zhang, S. Z. Zhang, and C. Q. Zhu, Anal. Methods, 2014, 6, 2499.

14. R. E. Ionescu, S. Cosnier, and R. S. Marks, Anal. Chem., 2006, 78, 6327.

15. J. H. Yu, S. Choi, and R. M. Dickson, Angew. Chem., Int. Ed., 2009, 48, 318.

16. J. T. Petty, J. Zheng, N. V. Hud, and R. M. Dickson, J. Am. Chem. Soc., 2004, 126, 5207.

17. C. M. Ritchie, K. R. Johnsen, J. R. Kiser, Y. Antoku, R. M. Dickson, and J. T. Petty, J. Phys. Chem. C, 2007, 111, 175.

18. C. H. Fan, K. W. Plaxco, and A. J. Heeger, J. Am. Chem. Soc., 2002, 124, 5642.

19. M. M. Bushey and J. W. Jorgenson, J. Microcolumn Sep., 1990, 2, 293

20. D. L. Liao, J. Chen, W. Y. Li, Q. F. Zhang, F. Y. Wang, Y. X. Li, and C. Yu, Chem. Commun., 2013, 49, 9458.

21. Y. Y. Wang, Y. Zhang, and B. Liu, Anal. Chem., 2010, 82, 8604.

22. L. Zhang, J. Zhu, S. Guo, T. Li, J. Li, and E. K. Wang, J. Am. Chem. Soc., 2013, 135, 2403.

23. M. Wang, X. G. Gu, G. X. Zhang, D. Q. Zhang, and D. B. Zhu, Anal. Chem., 2009, 81, 4444.

24. B. A. Zaccheo and R. M. Crooks, Anal. Chem., 2011, 83, 1185.

25. Q. F. Zhang, W. Y. Li, J. Chen, F. Y. Wang, Y. Wang, Y. Chen, and C. Yu, Chem. Commun., 2013, 49, 3137.

26. J. M. Busnel, S. Descroix, T. Le Saux, S. Terabe, M. C. Hennion, and G. Peltre, Electrophoresis, 2006, 27, 1481.

27. B. Y. Han and E. K. Wang, Biosens. Bioelectron., 2011, 26, 2585.

28. X. Li, S. J. Zhu, B. Xu, K. Ma, J. H. Zhang, B. Yang, and W. J. Tian, Nanoscale, 2013, 5, 7776.

29. Q. Zhu, R. Y. Zhan, and B. Liu, Macromol. Rapid Commun., 2010, 31, 1060.

30. W. X. Xue, G. X. Zhang, D. Q. Zhang, and D. B. Zhu, Org. Lett., 2010, 12, 2274.

31. H. X. Wang and T. B. Ng, Biochem. Biophys. Res. Commun., 2006, $342,349$. 